\title{
JPSE
}

(Journal of Physical Science and Engineering)

\section{Control of Air Pressurizer Levels on Pressurized Water Reactor (PWR) with Fractional Order PID Control System}

\begin{tabular}{l}
\hline Received \\
17 September 2020 \\
Revised \\
19 October 2020 \\
Accepted for Publication \\
21 October 2020 \\
Published \\
23 October 2020 \\
\end{tabular}

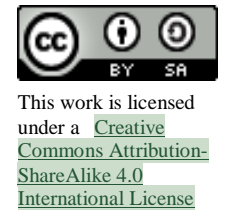

\author{
R Damayanti ${ }^{1 *}$, A Halim ${ }^{1}$, and S Bakhri ${ }^{2}$ \\ 1. Department of Electrical Engineering, Faculty of Engineering, Universitas Indonesia, J1. Letnan \\ Jenderal Dokter Sjarif Tjaheb, Depok, 16424, Indonesia. \\ 2. Nuclear Reactor Technology and Safety Center, National Nuclear Energy Agency, Serpong \\ PUSPIPTEK Area - Gedung 80, South Tangerang, 15310, Indonesia. \\ *E-mail: rissa.damayanti@ui.ac.id
}

\begin{abstract}
The water level control system in the pressurizer is carried out for safety purposes when the PWR reactor is operating. Control is done by maintaining the water level in the pressurizer at a certain level. The height of the water level in the pressurizer will change according to the conditions of the nuclear reactor. This research aimed to obtain the best safety control system using the fractional order PID (FOPID) control system and prove that using the control system will provide better results than other existing system applications. In this research, the optimum gain control of FOPID is obtained with $K_{p}=$ 416.4, $K_{i}=416.4, K_{d}=104.1, \lambda=0.15$, and $\mu=1.9$, which results in 324 times faster settling time and maximum overshoot 1.5 times lower when compared to conventional PID controllers combined with CMAC.

Keywords: Pressurizer, PWR, proportional integral derivative (PID), FOPID.
\end{abstract}

\section{Introduction}

Pressurizer is part of the pressurized water reactor (PWR) that functions to maintain the pressure in the primary cycle to remain at a certain price or set point [1], [2]. This may occur if the water surface level (liquid level) is constant. Looking at the control system method applied to the water level control system, the the PWR utilizes proportional (P), proportional-integral (PI) and proportional-integral and derivative (PID) controllers. The PID control method still produces an unstable response when given more input parameters [3]. This affects the overshoot or maximum misses from the set point, which depends on how far the accuracy of the $K_{p}, K_{i}$, and $K_{d}$ parameters is determined [2]-[4].

This research aims to address the existing problems by using the fractional order PID (FOPID) control system and to prove that using the control system will provide better results than the system application using current control methods. In this research, two things will be conducted. First, this research will discuss and describe the performance of FOPID control system for various configuration variations so that a complete understanding of the FOPID controller characteristics can be obtained, and so can the best FOPID parameter configuration in controlling the surface level of pressurizer water at PWR. Second, the pressurizer water level control system designed in the previous studies will be compared with the results of this research. The comparison is made using the following parameters: the value of the rise time, the settling time, and the maximum overshoot percentage. The results of this research are expected to have a positive impact on the understanding of the water level control system based on FOPID and be able to be properly applied.

\section{Method}

\subsection{Pressurizer}

In a PWR type nuclear power plant system, the cooling system used water with high pressure with the primary system having a closed cycle circulation [1], [2]. To prevent the heat transferred from the reactor from boiling, this high pressure is needed. A nuclear power plant only has one pressurizer unit. Figure 1.a shows the location of a pressurizer on the PWR [1]. In the pressurizer block, there are two parts, namely a part filled with water and the one containing hot steam. During steady state condition, the ratio of water with saturation condition is around $60 \%$, while with hot vapor condition is around 
$40 \%$. Then, to keep the steam stable in order not too hot, there is a spray on the pressurizer system. In addition, there is a spare heating system that functions to maintain the steam stability when there is a pressure drop to keep the heat transmitted to the steam generator stable. In this case, a pressurizer is very important to prevent over-pressure from happening and to maintain the stability of the heat generated from the reactor core so that the coolant water does not boil. Furthermore, the pressurizer system is also used as a safety system, namely serving as a barrier to prevent over-pressure from happening which may cause the environmental radionuclide releases to emerge [5].

Details of the components that make up the pressurizer are shown in Figure 1.a. The main pressurizer system is composed of several components, including pressurizer vessels, surge lines, electric immersion heaters, and spray systems. This pressurizer system is equipped with several valves that are not shown in Figure 1.a, including safety valves, isolation valves and relief valves as well as a pressurizer relief tank that functions as a control system and primarily as security and safety support systems. Figure 1.b [1] shows that there are two types of surge lines, namely the in-surge volume and the out-surge volume, in which the in-surge volume refers to the condition when the primary coolant water enters, while the out-surge volume being the condition when the primary coolant water comes out to set the temperature of the coolant water at a certain set point determined due to a change in load. In other words, changes in volume due to temperature changes affect the condition of the water level and the gas pressure in the pressurizer.

Control the water level in this system by integrating it into the coolant water filling system setting in the primary loop through the height of chemical and volume control system (CVCS). If the water level of the pressurizer decreases past the predetermined set point, a certain amount of water will be added, and if the water level increases beyond the predetermined set point, a certain amount of water will be removed from the cooling system [2]. This process is shown in Figure 2. The level control system is carried out with three control inputs among others: water level input with its reference level, filling rate, and flow extraction rate [6]. The control system is also equipped with a safety system for when a significant drop in the water level occurs, the isolation system will close the pressurizer and turn off the heater so it does not burn.

So as to maintain the water level according to its reference, the filling process was carried out by changing the valve angle for filling the flow. The change in the average water temperature of the reactor coolant greatly affected the reference set point of the water level. The expansion of the water volume resulted in the height of the water level since the average temperature of the coolant rose, and vice versa. Thus, control can also be done by utilizing expansion or contraction of the primary coolant by monitoring changes in average temperature [7].

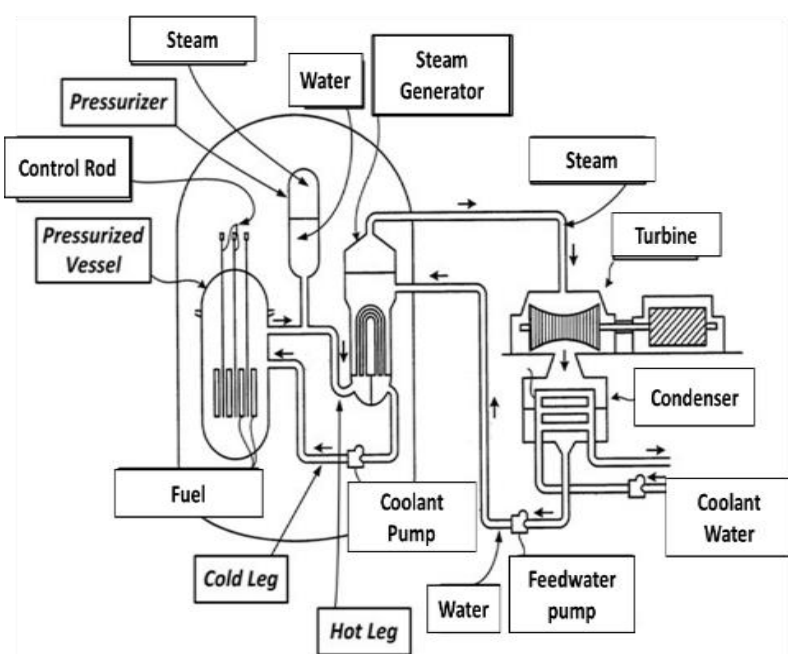

(a)

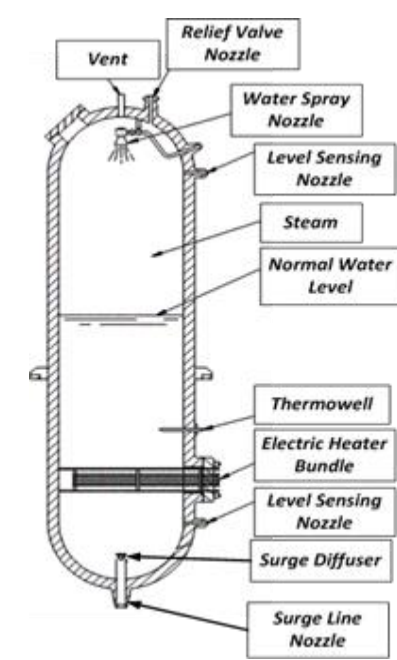

(b)

Figure 1. (a) Position of pressurizer in the PWR type nuclear reactor set, and (b) details of construction. 


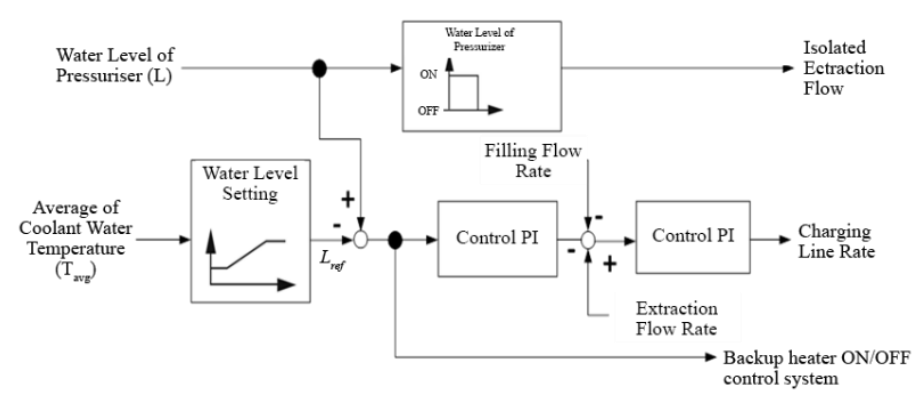

Figure 2. Water level control system in a pressurizer.

To facilitate the simulation of water level control in the PWR pressurizer, several studies have proposed a transfer function to model a pressurizer [8], [9]. This transfer function was made in the form of a pressurizer independent model in the PWR regardless of the interaction of the influence of the reactor core, steam generator, and load demand. The literature shows that the pressurizer behavior is composed of the equations of mass conservation, energy conservation, and total volume conservation, one of which is shown in equation 1 [9]. This equation shows the dynamic modelling of the pressurizer level height $(d z / d t)$ by considering several parameters such as the area of the pressurizer (diameter parameter $D$ in meters), mass flow rate of surge line coolant $\left(M_{l}\right.$ in $\left.\mathrm{kg} / \mathrm{m}^{3}\right)$, volume of pressurizer water $\left(v_{l}\right.$ in $\left.\mathrm{m}^{3}\right)$, pressurizer pressure ( $p$ in MPa), and water enthalpy at surge ( $h$ in units of $\mathrm{kJ} / \mathrm{kg}$ ).

$$
\frac{d z}{d t}=-\frac{4}{\pi D^{2}}\left[v_{1} \frac{d M_{1}}{d t}+M_{1}\left(\frac{d v_{1}}{d p} \frac{d p}{d t}+\frac{d v_{1}}{d h_{1}} \frac{d h_{1}}{d t}\right)\right]
$$

Furthermore, the previously mentioned linearized differential pressurizer equation is transformed into the form of Laplace obtained from the previous studies as seen in equation 2 [9].

$$
H(s)=\frac{10.05}{s^{2}+2 s+10.5} \frac{0.003}{s}
$$

The transfer function in equation 2 will be used to simulate the characteristics of the water level in the pressurizer, which is then controlled by the FOPID controlling method.

\subsection{PID Controllers}

PID (Proportional, Integral, and Derivative) is a control with parameters P, I, and D with a mathematical model consisting of input gain + integral + derivative [10]. PID is a control method with a good mathematical model because the error can be changed to near zero, stability control can be achieved by equating the value of the process variable with the set point value [11]. The block diagram of the PID control on the pressurizer in general can be seen in Figure 3. An important point to note is that the set point of the pressurizer water level when calculated based on the temperature function can be seen in Figure 4.b.

Definition of PID $(t)$ is as the output control results, while as the PID algorithm standard is

$$
u(t)=K_{p} e(t)+K_{i} \int_{0}^{t} e(\tau) d t+K_{d} \frac{d}{d t} e(t)
$$

in which $e(t)$ is the input signal and $u(t)$ is the output signal. Based on equation 3 , the transfer function of PID controllers is

$$
G(s)=\frac{U(s)}{E(s)}=K_{p}+\frac{K_{i}}{s}+K_{i} s
$$




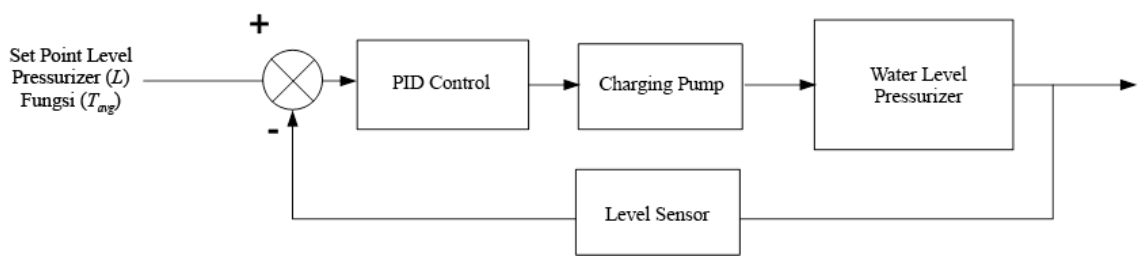

Figure 3. Diagram of pressurizer control with PID.

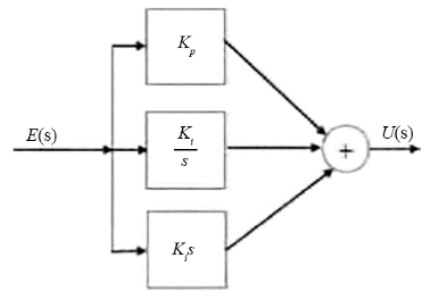

(a)

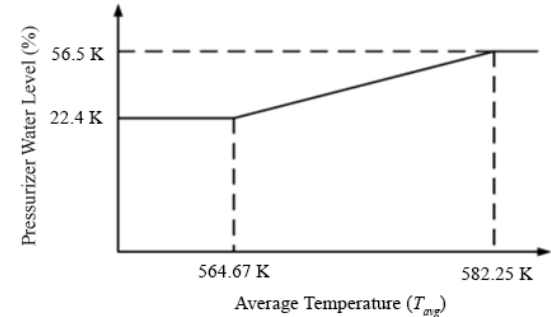

(b)

Figure 4. (a) Diagram of PID controller block, and (b) eexample of pressurizer set point level as an average temperature function of primary coolant in the PWR.

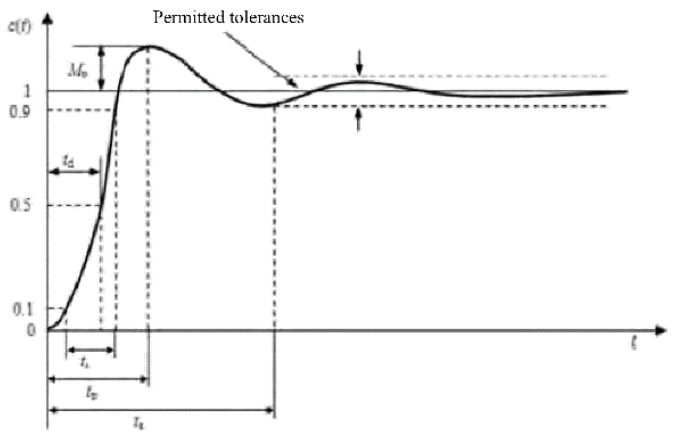

Figure 5. Specifications of transient response.

To find out the performance of a control system is not only conducted by observing its stability, but also by observing several other elements generally called transient response characteristics, in which the transient response is a system response that takes place from initial conditions to final conditions [1], [2].

\subsection{Fractional Calculus}

The differintegral operator denoted as ${ }_{a}^{t} D^{\alpha}$ is a combination of differential-integral operators used in fractional calculus. This operator combines the fractional derivative and fractional integral into one expression and is defined as follows [12]

$$
{ }_{a} D_{t}^{\alpha}=\left\{\begin{array}{ccc}
\frac{d^{\alpha}}{d t^{\alpha}} & , \operatorname{Re} & \alpha>0 \\
1 & , \operatorname{Re} & \alpha=0 \\
\int_{\alpha}^{t}(d \tau)^{-\alpha}, & \operatorname{Re} & \alpha<0
\end{array}\right.
$$


in which $\alpha \in \mathbb{C}$ is a fractional order and $\mathrm{a}, \mathrm{t}$ is the operational limit. There are several definitions of fractional derivative, one of which is that by Caputo as follows

$$
{ }_{a} D_{t}^{\alpha}(t)=\frac{1}{\Gamma(m-\alpha)} \int_{0}^{t} \frac{f^{(m)}(\tau)}{(t-\tau)^{\alpha-m+1}}, \quad m-1<\alpha<m
$$

in which $\mathrm{m}$ is the first integer greater than $\alpha$. Laplace ttransformation of eequation 6 is

$$
\mathrm{L}\left\{{ }_{0} D_{t}^{\alpha} f(t)\right\}=s^{\alpha} F(s)-\sum_{k=0}^{n-1} s^{\alpha-k-1} f^{(k)}(0), \quad n-1<\alpha \leq n
$$

in which $\mathrm{n} \in \mathbb{N}$. For the initial condition of zero system, eequation 7 became

$$
\mathrm{L}\left\{_{0} D_{t}^{\alpha} f(t)\right\}=s^{\alpha} F(s)
$$

\subsection{Fractional Order PID (FOPID)}

In 1999, a modification of PID controllers was developed by adding two new parameters, namely $\lambda$ and $\mu$, in which each constitutes integral and derivative order [13]. The controllers are called fractional order PID $\left(\mathrm{PI}^{\lambda} \mathrm{D}^{\mu}\right)$ controllers, being a combination of PID controllers and fractional calculus concept. The mathematical model of FOPID controllers is

$$
u(t)=K_{p} e(t)+K_{i} D^{-\lambda} e(t)+K_{d} D^{\mu} e(t)
$$

in which $D^{\alpha}$ is the differintegral operator with $\alpha$ order, thus, based on equation 9 , transfer function of FOPID controllers is obtained, as follows

$$
G_{c}(s)=\frac{U(s)}{E(s)}=K_{p}+\frac{K_{i}}{s^{\lambda}}+K_{d} s^{\mu}, \quad(\lambda, \mu>0)
$$

In the PID controllers, there are three parameters, namely $K_{p}, K_{i}$, and $K_{d}$ whereas the FOID controllers have two more parameters, namely $\lambda$ and $\mu$. The control parameter tuning process uses Ziegler-Nichols method to obtain the best and the most precise parameter value to use in this process [14].

\subsection{Fractional Order PID (FOPID) Tuning}

This method has two ways, the first is with the step response model and the second is the close loop method. Both methods are intended to produce a system response with a maximum spike of $25 \%$.

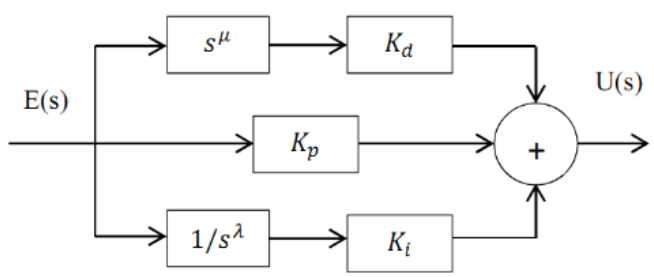

Figure 6. Diagram fractional order $\mathrm{PID}\left(\mathrm{PI}^{\lambda} \mathrm{D}^{\mu}\right)$ controllers of block. 


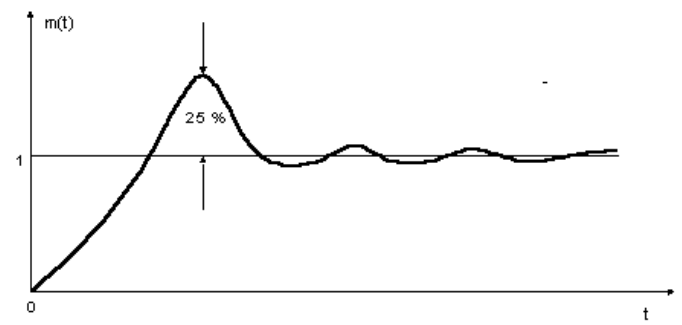

Figure 7. Unit phase response curve showing a maximum spike of $25 \%$.

Table 1. PID tuning parameters with close loop method.

\begin{tabular}{cccc}
\hline Controller & $\mathrm{P}$ & $\mathrm{PI}$ & $\mathrm{PID}$ \\
\hline$K p$ & $0.5 K$ & $0,45 K$ & $0.6 K$ \\
\hline$T i$ & 0 & $P_{u} / 1.2$ & $P_{u} / 2$ \\
\hline$T d$ & 0 & 0 & $P_{u} / 8$ \\
\hline
\end{tabular}

\subsection{Close Loop Method}

Close loop method was used to conduct PID tuning in this research. The followings are several procedures to carry out the method, i.e. (a) turning off the $K_{i}$ and $K_{d}$ variables in advance, only using constant gain in the close loop system, (b) providing the setpoint value with the step unit signal, (c) setting the $K$ value (constant gain) to make the system output oscillate, (d) determining the period of the $P_{u}$ output signal, and (e) from the $P_{u}$ output signal period, the PID parameters can be determined through the Table 1 [15].

The design and simulation of this control began with performing PID controllers' parameter tuning process, namely control simulation of $K_{p}, K_{i}$, and $K_{d}$ was conducted to the system so that system response with PID controllers was obtained. Tuning was carried out with the second method of ZieglerNichols method. Next, the performance of PID controllers towards the system was fixed using FOPID controllers, that is by adding two new parameters, namely $\lambda$ and $\mu$. Simulation included the control conditionusing PID and FOPID. Based on the results obtained, an analysis was carried out to determine the best controller among several controller designs made to be applied to the system [16], [17]. The diagram of closed loop control system block of the PWR pressurizer water level control system as shown on Figure 8.

\section{Results and Discussion}

This section explains the results of PWR pressurizer control system designs with PID and FOPID controllers as well as the analysis on the performance of control system results. The transfer function of the plant model utilized is in equation 2 . The design parameters used were as follows maximum settling time $\leq 300$ seconds and maximum overshoot $\leq 20 \%[10]$.

\subsection{Ziegler Nichols Tuning}

After using a mathematical model of the PWR level pressurizer system with the Laplace transfer function mentioned earlier, an analysis was then carried out. The analysis of the plant model in the frequency domain shows on Figure 9.a and 9.b.

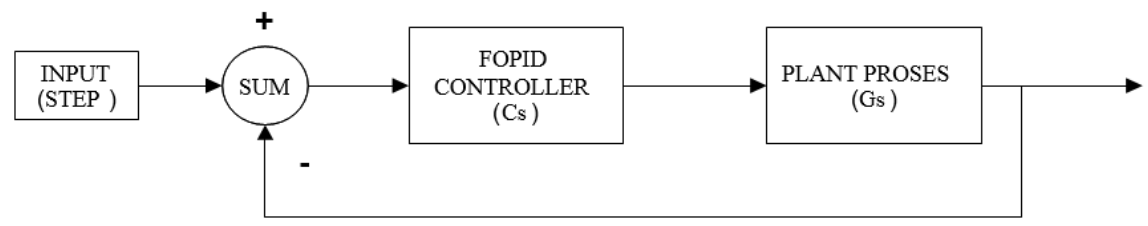

Figure 8. The diagram of closed loop control system block of the PWR pressurizer water level control system. 


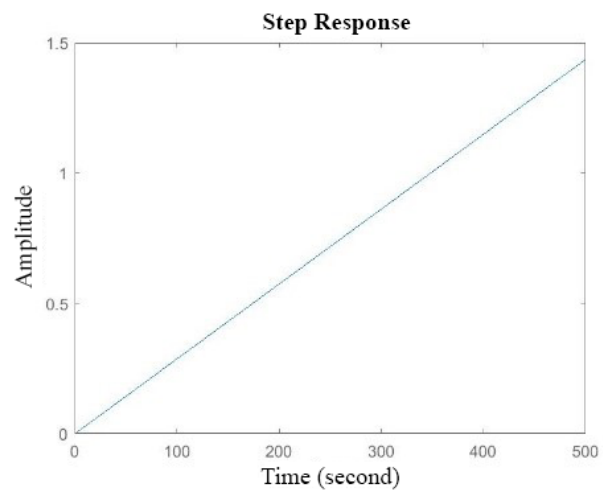

(a)

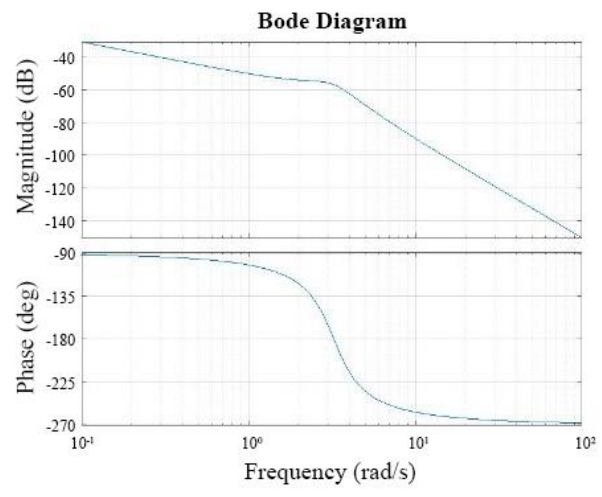

(b)

Figure 9. (a) Open loop plant step response without controller, (b) Bode plot of the plant system without controllers.

From the bode plot above, margin gain value as much as $56,9 \mathrm{~dB}$ and phase margin as much as $90 \mathrm{deg}$ were obtained. It can be seen that the system is a critical stable system, therefore, a control system that can make the system have good stability is necessary [18].

\subsection{Controller Designs}

If the step plant obtains the results as shown in Figure 9.a, tuning cannot be conducted using the first method of $\mathrm{ZN}$ tuning (step response method), in this case, what can be done is conducting tuning using the second method of $\mathrm{ZN}$ tuning (close loop response method). This second tuning method is carried out by adding a constant gain $(K)$ so that the system output becomes an oscillation, providing a set-point with the step unit signal, determining the period of the $P_{u}$ output signal [19], [20]. After determining the $P_{u}$ period, the parameter value according to table 1 can be calculated or determined. The constant gain value $(K)$ during the closed loop oscillation system can be found through the root locus shown on Figure 10.

From the root locus, the gain value $\mathrm{K}$ as much as 694 with an angular frequency of $3.24 \mathrm{rad} / \mathrm{s}$ was obtained. The next step was to look for the close loop response of the plant system to get the $\mathrm{Pu}$ value, in which the $\mathrm{Pu}$ value was used to calculate the value of $\mathrm{Ti}(\mathrm{Pu} / 2)$ and $\mathrm{Td}(\mathrm{Pu} / 8)$, by performing the following simulation as shown on Figure 11.

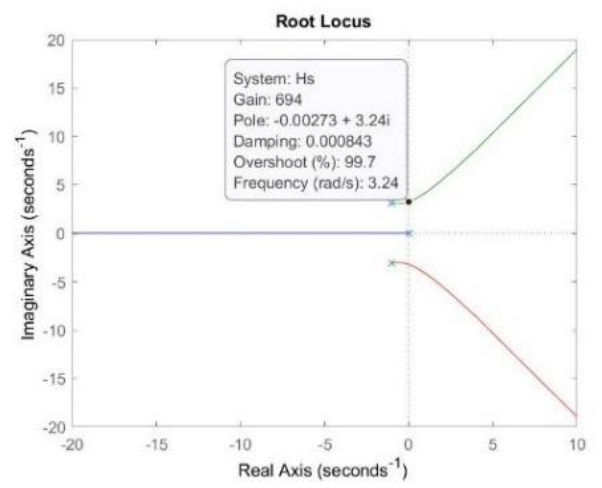

Figure 10. Root locus plant without controllers

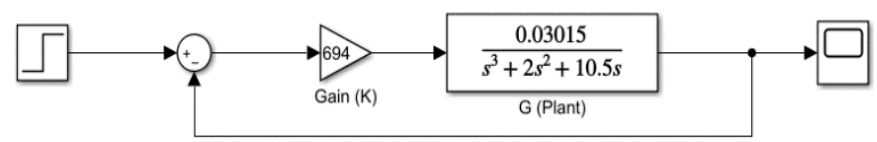

Figure 11. The series of the second method of simulink ZN tuning. 


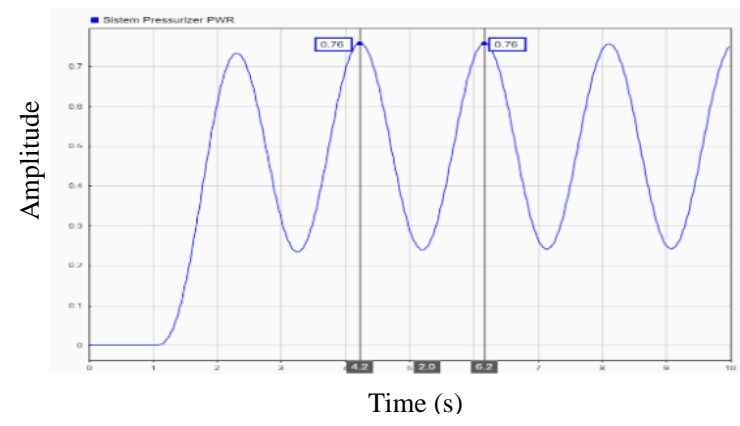

Figure 12. Response of PWR pressurizer system from the Second Method of ZN Tuning.

After conducting tuning using the second method of $\mathrm{ZN}$ tuning, the following parameter values were obtained $K_{p}=416.4, K_{i}=426.4$, and $K_{d}=104.1$. Therefore, the transfer function of PID controllers is

$$
G_{c \mathrm{PID}}(s)=416.4+\frac{416.4}{s}+104.1 s
$$

The transfer function of the system provided with PID controllers (transfer function of closed loop system) can be write

$$
G(s)=\frac{104.1 s^{2}+416.4 s+416.4}{33 s^{4}+66 s^{3}+452.1 s^{2}+416.4 s+416.4}
$$

Next, performing tuning for parameter $\lambda$ and $\mu$. The first step was to initiate the initial condition using the value of $\lambda \leq 1$ and the value of $\mu \leq 2$. Then, simulation was conducted by combining the value of $\lambda$ and $\mu$, so that a better performance than that of PID controllers was obtained.

Table 2. The results of $\mathrm{PD}^{\mu}$ controllers response using the variation of value of $\mu \leq 2$.

\begin{tabular}{cccccc}
\hline $\begin{array}{c}\text { Value of } K_{p}(\mathrm{P}) \\
\text { Controller }\end{array}$ & $\begin{array}{c}\text { Value of } K_{d}(\mathrm{D}) \\
\text { Controller }\end{array}$ & Value of $\mu$ & $\begin{array}{c}\text { Rise Time } \\
\text { (second) }\end{array}$ & $\begin{array}{c}\text { Max. } \\
\text { Overshoot (\%) }\end{array}$ & $\begin{array}{c}\text { Settling Time } \\
\text { (second) }\end{array}$ \\
\hline 416.4 & 104.1 & 0.1 & 0.59 & 21.3 & Oscillation \\
\hline 416.4 & 104.1 & 0.5 & 0.57 & 18.4 & Oscillation \\
\hline 416.4 & 104.1 & 0.9 & 0.66 & 6.9 & 19.2 \\
\hline 416.4 & 104.1 & 1.4 & 1.9 & 0.5 & 9.1 \\
\hline 416.4 & 104.1 & 1.9 & 1.8 & 3.6 & 9.8 \\
\hline
\end{tabular}

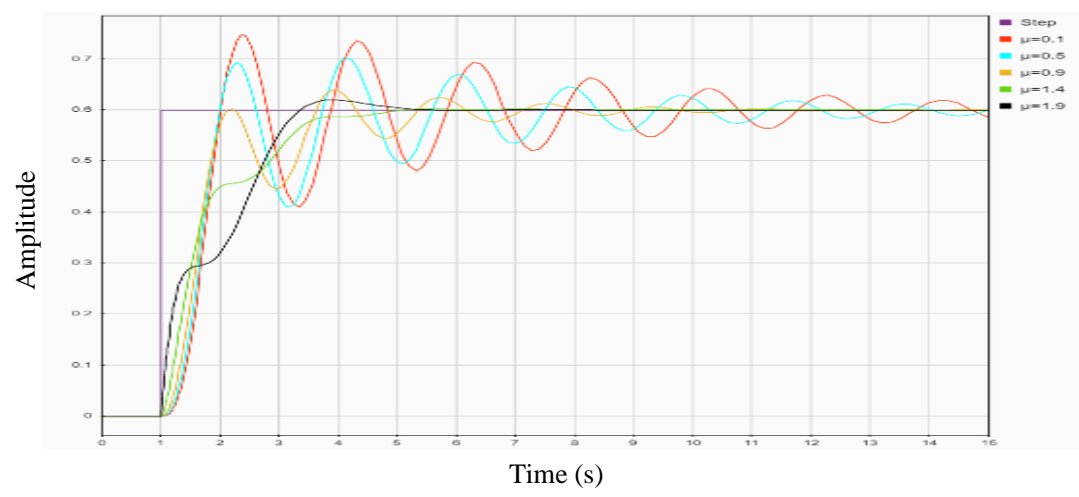

Figure 13. Chart showing the $\mathrm{PD}^{\mu}$ controllers response with the variation of value of $\mu \leq 2$. 
Table 3. The results of $\mathrm{PI}^{\lambda}$ controllers response using the variation of value of $\lambda \leq 1$.

\begin{tabular}{cccccc}
\hline $\begin{array}{c}\text { Value of } K_{p}(\mathrm{P}) \\
\text { Controller }\end{array}$ & $\begin{array}{c}\text { Value of } K_{i}(\mathrm{I}) \\
\text { Controller }\end{array}$ & Value of $\lambda$ & $\begin{array}{c}\text { Rise Time } \\
\text { (second) }\end{array}$ & $\begin{array}{c}\text { Max. } \\
\text { Overshoot (\%) }\end{array}$ & $\begin{array}{c}\text { Settling Time } \\
\text { (second) }\end{array}$ \\
\hline 416.4 & 416.4 & 0.15 & 0.33 & 69.4 & Oscillation \\
\hline 416.4 & 416.4 & 0.30 & 0.42 & 39.8 & Oscillation \\
\hline 416.4 & 416.4 & 0.50 & 0.65 & 14.4 & Oscillation \\
\hline 416.4 & 416.4 & 0.75 & 0.48 & 95.0 & 67.8 \\
\hline 416.4 & 416.4 & 0.90 & 0.51 & 84.2 & 39.0 \\
\hline
\end{tabular}

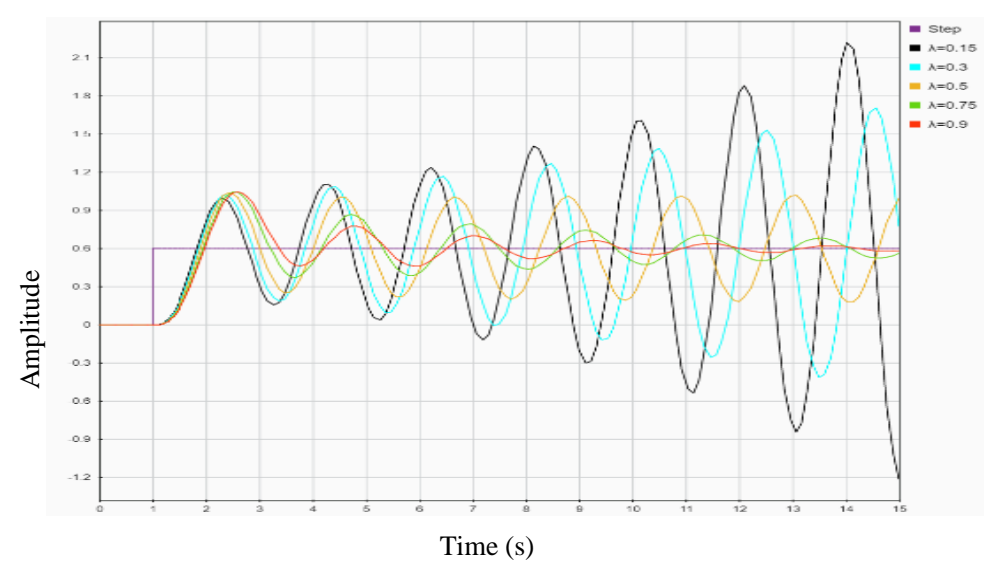

Figure 14. Chart showing the $\mathrm{PI}^{\lambda}$ controllers response using the variation of value of $\lambda \leq 1$.

Table 4. The results of FOPID controller response with the variation of value of $\lambda \leq 1$ and the value of $\mu \leq 2$.

\begin{tabular}{cccccccc}
\hline$K_{p}(\mathrm{P})$ & $K_{i}(\mathrm{I})$ & $K_{d}(\mathrm{D})$ & $\lambda$ & $\mu$ & $\begin{array}{c}\text { Rise Time } \\
\text { (second) }\end{array}$ & $\begin{array}{c}\text { Max. } \\
\text { Overshoot }(\%)\end{array}$ & $\begin{array}{c}\text { Settling Time } \\
\text { (second) }\end{array}$ \\
\hline 416.4 & 416.4 & 104.1 & 0.15 & 0.1 & 0.21 & 102.0 & Oscillation \\
\hline 416.4 & 416.4 & 104.1 & 0.3 & 0.5 & 0.31 & 71.7 & Oscillation \\
\hline 416.4 & 416.4 & 104.1 & 0.5 & 0.9 & 0.47 & 50.7 & 35.8 \\
\hline 416.4 & 416.4 & 104.1 & 0.75 & 1.4 & 0.72 & 24.3 & 14.2 \\
\hline 416.4 & 416.4 & 104.1 & 0.9 & 1.9 & 1.20 & 55.5 & 22.9 \\
\hline 416.4 & 416.4 & 104.1 & 0.15 & 1.9 & 1.00 & 18.4 & 11.0 \\
\hline 416.4 & 416.4 & 104.1 & 1.00 & 1.0 & 0.56 & 30.9 & 13.9 \\
\hline
\end{tabular}

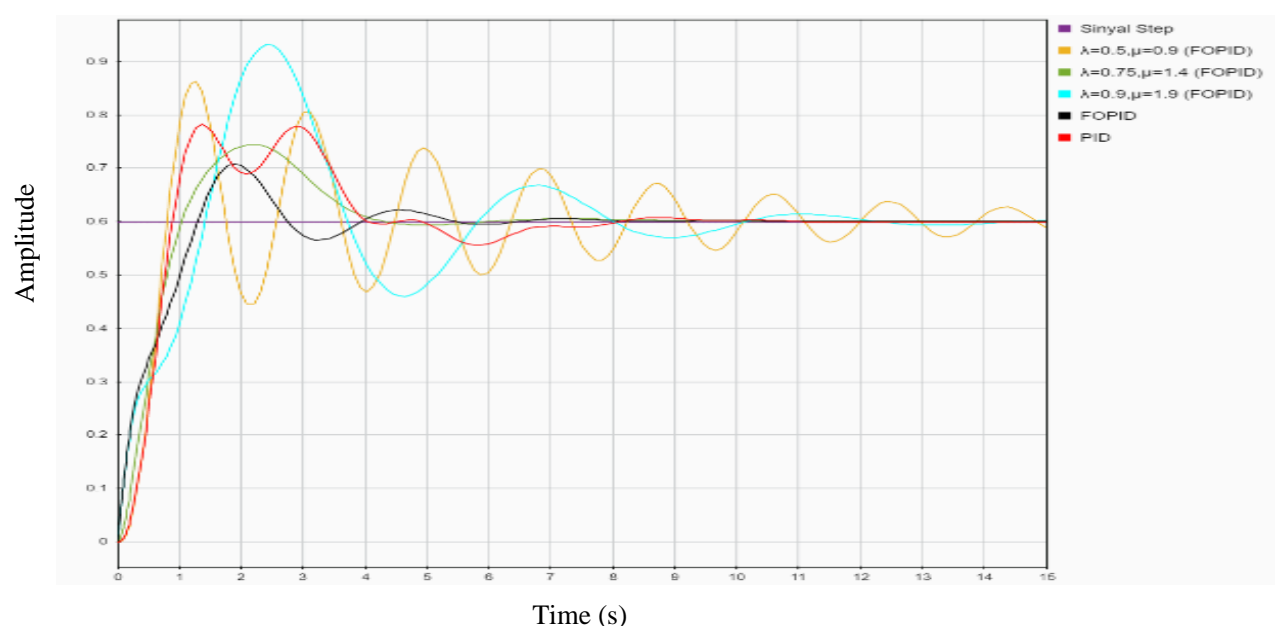

Figure 15. Chart showing the FOPID controller response with the variation of value of $\lambda \leq 1$ and the value of $\mu \leq 2$. 
From the results as shown in Table 2-6, the best transient response was obtained, that is with the value of $\lambda=0.15$ and $\mu=1.9$ in which the water level subsystem in the PWR pressurizer was able to achieve stability at a set point level (normalized) of $0.6 \%$ with a settling time of 11 seconds and a maximum overshoot of $18.4 \%$. From the simulation results, there was actually a transient response with a faster settling time and a smaller maximum overshoot, however, the resulting transient response was relatively unstable. the transfer function of FOPID controllers for the water level subsystem in the PWR pressurizer is

$$
G_{c \mathrm{FOPID}}(s)=416.4+\frac{416.4}{s^{0.15}}+104.1 s^{1.9}
$$

The closed loop transfer function for the system provided with FOPID controllers can be describes in

$$
G(s)=\frac{104.1 s^{2.05}+416.4 s^{0.15}+416.4}{33 s^{3.15}+66 s^{2.15}+104.1 s^{2.05}+348 s^{1.15}+416.4 s^{0.15}+416.4}
$$

The response of the system equipped with PID integer controllers and that with FOPID ones, can be seen in the Figure 16. Comparison to the results of previous studies in Figure 17.a [9] and 17.b [10]. From the results of simulation, it can be noted that the response of FOPID controllers had a faster settling time than that of PID integer in which the settling time of the latter was 13.9 seconds and with the maximum overshoot of $30.9 \%$, if compared to PI controllers in the previous studies [10] that recorded a settling time of 12.2 seconds and with the maximum overshoot of $22.2 \%$ or PID integer that was combined with CMAC in the previous studies [2] with its settling time of 3,570 seconds and with the maximum overshoot of $24.3 \%$. These parameter values of PID integer combined with CMAC are unacceptable if compared to several requirements of a pressurizer in the PWR, one of which is having settling time not more than 300 seconds.

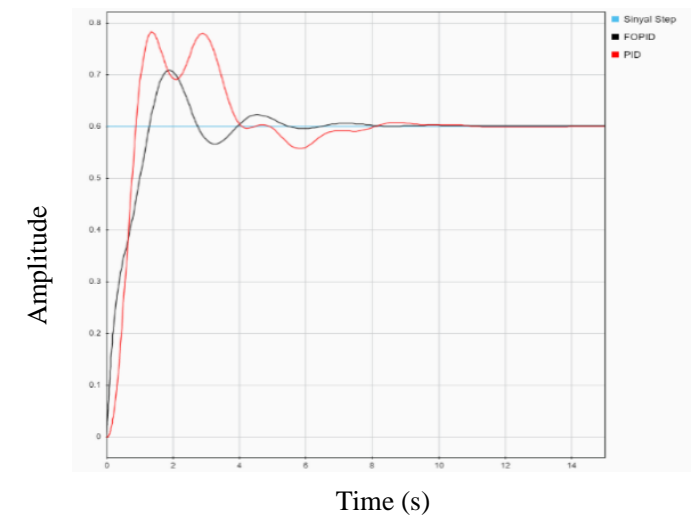

Figure 16. Comparison of response between PID integer and FOPID ccontrol ssystem.

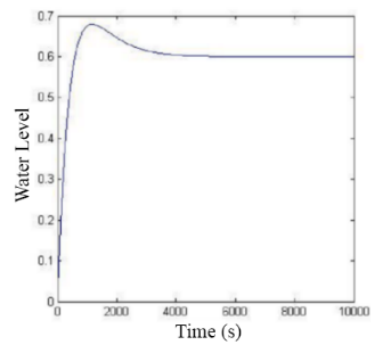

(a)

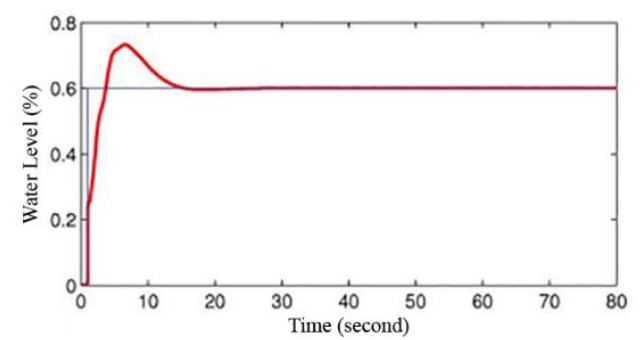

(b)

Figure 17. (a) The results of the response simulation using CMAC and PID methods in the previous studies, (b) The results of level controlling simulation with PI controllers in the previous studies. 


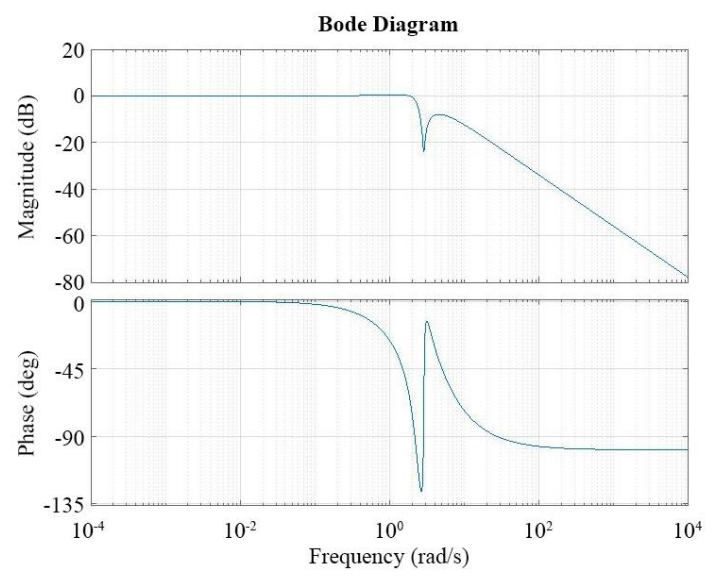

Figure 18. Bode plot of system equipped with FOPID controllers.

\subsection{Analysis on Stability}

The analysis on stability for the system equipped with FOPID controllers (close loop system) was conducted through domain frequency parameters, that is using the following bode plot diagram as shown on Figure 18. From the bode plot, the values of gain margin $(\mathrm{Gm})$ as much infinity, phase margin (Pm) 117.2 were obtained. Therefore, the results of analysis plot show that the system provided with FOPID controllers reached a stable state, since both margins had positive values or greater than 0 (zero). Subsequently, verification was carried out by testing the stability using fomcon toolbox, obtaining results shown on Figure 19. The system was stable, with the following parameter $K=1, q=0.05$, and $e r r=6.5787 \times 10^{-10}$.

\section{Conclusion}

This research concluded that if the fractional order PID (FOPID) is applied in real life to control the PWR pressurizer level, this method will be very capable of controlling the water level control process in the PWR pressurizer in accordance with one of the requirements, in which the maximum settling time is not more than 300 seconds. The optimum gain configuration for the FOPID controller is $K_{p}=$ 416.4, $K_{i}=416.4, K_{d}=104.1, \lambda=0.15$, and $\mu=1.9$ that generates the settling time as much as 324 times faster and the maximum overshoot as much as 1.5 times lower if compared with the PID integer controllers when combined with CMAC in the previous studies.

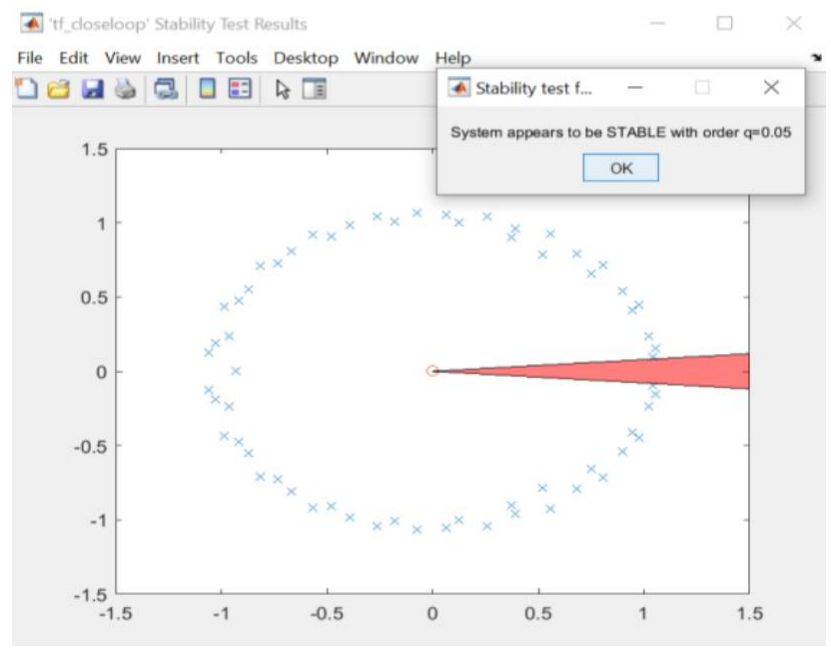

Figure 19. Stability test of the system with FOPID controllers. 


\section{References}

[1] G. D. Zhang, X. H. Yang, X. L. Ye, H. Xu, D. Q. Lu, and W. Chen, "Research on pressurizer water level control of pressurized water reactor nuclear power station," Energy Procedia, vol. 16, Part B, pp. 849-855, 2012.

[2] J. Yi, J. Ye, Y. Xue, X. Yang, and H. Qian, "Research on pressurizer water level control of nuclear reactor based on CMAC and PID controller," in 2009 Int. Conf. Artificial Intelligence and Computational Intelligence, vol. 3, 2009, pp. 8-11.

[3] M. V. de-Oliveira and J. C. S. de-Almeida, "Application of artificial intelligence techniques in modeling and control of a nuclear power plant pressurizer system," Prog. Nuclear Energy, vol. 63, pp. 71-85, 2013.

[4] Y. C. Wang, S. J. Wang, C. S. Chien, and S. C. Chiangb, "Analysis of pressurizer level control system using MAAP4 code," Nuclear Eng. Des., vol. 240, no. 1, pp. 160-165, 2010.

[5] C. L. Yu, T. C. Wang, and C. Y. Liu, "Numerical investigation on the influence of the type of PI controller combined with MAAP code on the steady-state performance of a nuclear power plant," Nuclear Eng. Des., vol. 343, pp. 248-256, 2019.

[6] R. Maerani and S. Bakhri, "Perbandingan sistem pengontrolan PID konvensional dengan pengontrolan CMAC, fuzzy logic, dan ANN pada water level pressurizer," SIGMA EPSILONBuletin Ilmiah Teknologi Keselamatan Reaktor Nuklir, vol. 17, no. 3, pp. 129-141, 2013.

[7] Y. Oka and K. Suzuki, Nuclear Reactor Kinetics and Plant Control. Tokyo: Springer, 2013.

[8] W. Zhou and X. Zhang, "The preliminary research of pressure control system danymic simulation for Ap1000 pressurizer based on parameter adaptive fuzzy PID control algorithm," in Electr. Eng. Control, Heidelberg, Germany, 2011, pp. 583-591.

[9] J. H. Ye, J. H. Yi, and H. Y. Ji, "Research on pressurizer water level control of nuclear reactor based on RBF neural network and PID controller," in 2010 Int. Conf. Mach. Learn. Cybern., vol. 3, 2010, pp. 1486-1489.

[10] M. Ali, "Pembelajaran perancangan sistem kontrol PID dengan Software MATLAB," $J$. Edukasi@Elektro, vol. 1, no. 1, , pp. 1-8, 2004.

[11] K. Ogata and Y. Yang, Modern Control Engineering, 5th ed. New Jersey: Prentice Hall, 2010.

[12] D. Xue, Y. Q. Chen, and D. P. Atherton, Linear Feedback Control Analysis and Design with MATLAB. Philadephia: SIAM, 2007.

[13] S. Bakhri, "Investigasi pengendalian level permukaan air pressurizer di PWR berbasis kendali proportional integral," J. Teknol. Reaktor Nuklir Tri Dasa Mega, vol. 16, no. 3, pp. 149-159, 2014.

[14] A. A. Dastjerdi, N. Saikumar, and S. H. H. Nia, "Tuning guidelines for fractional order PID controllers: rules of thumb," Mechatron., vol. 56, pp. 26-36, 2018.

[15] A. A. Dastjerdi, B. M. Vinagre, Y. Chen, and S. H. H. Nia, "Linear fractional order controllers; A survey in the frequency domain," Ann. Rev. Control, vol. 47, pp. 51-70, 2019.

[16] V. Shekher, P. Rai, and O. Prakash, "Tuning and analysis of fractional order PID controller," Int. J. Electron. Electr. Eng., vol. 5, no. 1, pp. 11-21, 2012.

[17] B. Özkan, "Control of an electromechanical control actuation system using a fractional order proportional, integral, and derivative-type controller," IFAC Proc., vol. 47, no. 3, pp. 4493-4498, 2014.

[18] D. Valerio and J. S. D. Costa, "Tuning of fractional PID controllers with Ziegler-Nichols-type rules," Signal Process., vol. 86, no. 10, pp. 2771-2784, 2006.

[19] P. Wang, J. He, X. Wei, and F. Zhao, "Mathematical modeling of a pressurizer in a pressurized water reactor for control design," Appl. Math. Model., vol. 65, pp.187-206, 2019.

[20] P. Wang, J. Wan, S. Wu, and F. Zhao, "A fuzzy-logic-based pressure setpoint modification method for pressurized water reactor pressurizers," Annals of Nuclear Energy, vol. 135, p. 106954, 2020. 